\title{
Vaping - not the smoke-ending panacea
}

For the past little while I have seen a variety of headlines in the various news and medical websites I look at daily. 'BAT not out of puff just yet ${ }^{\text {[1] }}$ came up on businesslive.co.za recently, reporting on British American Tobacco (BAT)'s purchase of e-cigarette seller Twisp in the light of falling cigarette sales. Trawling the internet has suggested to me that views on the efficacy of vaping as a way of helping people stop (or never start) smoking are equivocal - probably not surprising, given the paucity of evidence in either direction. But during the past month, different headlines have been appearing. 'US health officials warn against vaping' ${ }^{[2]}$ followed on from reports of more than 450 cases of severe pulmonary disease in the USA, ${ }^{[3]}$ across 33 states and including several deaths. Primary clinical features include respiratory symptoms such as cough, shortness of breath or chest pain, with some cases including gastrointestinal symptoms such as nausea, diarrhoea and vomiting. All the patients reported using e-cigarettes before symptoms started. These illnesses have caused health officials in the USA to warn people against using e-cigarettes while the cases are investigated.

I must admit to disliking vaping as much as I do cigarette smoking, and would not allow someone to vape in my home. But that prejudice aside, how is it that something as widely used by such an enormous range of people has simply been allowed onto the market with no thought of the potential for adverse effects? We know the dangers of nicotine (and the concomitant dangers of conventional cigarettes as a vehicle for the highly addictive substance), but we know little or nothing about the effects of the potentially toxic substances found in e-cigarettes. Vapers are essentially the guinea pigs for what has been described as one of the biggest experiments in human medical history. ${ }^{[4]}$ Those last words are from an article by Marika Sboros, published a couple of months before the reports of illness and death came from the USA.

In South Africa, the local e-cigarette market generated more than ZAR1.6 billion in sales in 2017, and at the time that this figure was published, projections were that it would triple over the next 10 years. Small wonder that BAT bought Twisp. But even before the reports in the USA, people were wary of the potential for adverse effects from vaping. The Heart and Stroke Foundation South Africa came out strongly against vaping, and the South African Thoracic Society is far from happy about it. As several people have pointed out, we need a few decades of data before we can draw any conclusions about whether or not vaping is safe. Scientists in the USA think that the cause of the illnesses seen may be contaminants or faulty devices, particularly as no cases have been seen elsewhere in the world and no single substance or e-cigarette product has been consistently associated with illness. ${ }^{[5]}$ However, it is possible that the flavourants used in vaping products may be to blame. The lack of data makes it impossible to make a conclusion one way or another we cannot say e-cigarettes are safer, but equally we cannot say that they are harmful. We do, however, know that smoking conventional cigarettes is harmful, and vaping may well be the lesser of two evils. Let's just hope it doesn't take as long as it did with tobacco to find out the harms. With this in mind, beware of the industry's efforts to obfuscate - which should be a lesson we have learnt by now.

\section{Bridget Farham \\ Editor \\ ugqirha@iafrica.com}

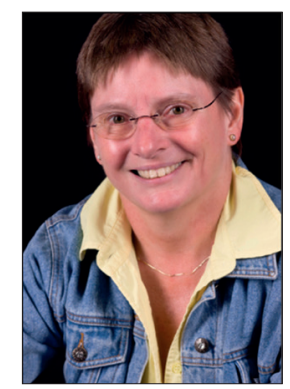

Njobeni S. BAT not out of puff just yet. Financialmail, 12 September 2019. https://www.businesslive. co.za/fm/money-and-investing/2019-09-12-bat-not-out-of-puff-just-yet/ (accessed 14 October 2019). Rocco M. US health officials warn against vaping. BusinessLIVE, 16 September 2019. https://www businesslive.co.za/ft/life/2019-09-16-us-health-officials-warn-against-vaping/ (accessed 14 October 2019). Hammond D. Outbreak of pulmonary disease linked to vaping. BMJ 2019;366:15445. https://do org $/ 10.1136 / \mathrm{bmj} .15445$

4. Sboros M. Is vaping a potential killer or a useful aid? BusinessDay, 28 July 2019. https://www. businesslive.co.za/bd/life/2019-07-29-marika-sboros-is-vaping-a-potential-killer-or-a-useful-aid/ (accessed 14 October 2019).

5. Centers for Disease Control and Prevention. Investigation notice: Outbreak of lung illness associated with using e-cigarette products. September 2019. www.cdc.gov/tobacco/basic information/ecigarettes/severe-lung-disease.html (accessed 14 October 2019).

S Afr Med J 2019;109(11):816. https://doi.org/10.7196/SAMJ.2019.v109i11.14440 